\title{
The Assessment of the Intrasubject Variability in Digoxin Absorption in Man from Two Oral Dosage Forms
}

\author{
avraham yacobi, Ph.D., Roger G. Stoll, Ph.D., George C. ChaO, Ph.D., \\ RONALD A. SCHWARTZ, Ph.D., DONALD J. WEIDLER, M.D., JAMES W. AYERS, Ph.D., \\ ERMELINDA SAKMAR, B.S., MARGARETTE HALLMARK, M.S., and JOHN G. WAGNER, Ph.D. \\ McGaw Park, III., and Ann Arbor, Mich.
}

\begin{abstract}
The reproducibility of drug absorption within a given subject as well as the evaluation of bioavailability of two digoxin dosage forms were studied. The data showed (a) a higher initial plasma digoxin concentration after the soft elastic gelatin (SEG) capsule; (b) a more irregular absorption after the tablet; (c) on the average, the coefficients of variation of individual plasma concentrations were lower after the capsule; and (d) for the capsule, the intrasubject variations of the peak plasma concentrations, time of peak, area under plasma concentrations-versus-time curve (AUC), and amount digoxin excreted in urine $\left(A_{e}\right)$ were on the average 60 per cent of the variations in the tablet parameters. The ratios of $A \cup C$ and $A_{0}$ for capsule/tablet were essentially unity, indicating that the amount digoxin absorbed from the 0.4-mg digoxin SEG capsule is identical to that from a $0.5-\mathrm{mg}$ standard reference tablet.
\end{abstract}

$\mathrm{T}_{\mathrm{s}}^{\mathrm{t}}$ HE bioavailability of digoxin from an oral dosage form is quite complex. Digoxin tablets, for instance, have shown serious bioavailability deficiencies. In addition to these shortcomings there are usually substantial inter- and intrasubject variations in bioavailability. Therefore, a rigorous assessment of bioavailability of a digoxin dosage form may necessitate a new investigational approach and a study design which allows for determination of variations in absorption of the drug within the same subjects. This is also important for evaluation of a new design form which contains a relatively insoluble drug.

Newly developed soft elastic gelatin (SEG) capsules dosage forms have been shown to possess superior bioavailability

From Research and Development Department, American Critical Care, McGaw Park, MI., and The Upjohn Center for Clinical Pharmacology, The University of Michigan, Ann Arbor, Mich.

July 1981 to the tablets. ${ }^{1-7}$ One such capsule has been recently developed with excellent relationship between in vivo bioavailability parameters and its in vitro dissolution characteristics. ${ }^{8}$ The purpose of this investigation was (a) to compare the bioavailability of the newly developed digoxin SEG capsule to standard reference tablet; and (b) to assess the reproducibility of digoxin absorption within a given subject with respect to peak plasma concentration, area under plasma concentration-versus-time curve $(A U C)$, and amount digoxin excreted in urine following administration of the two dosage forms. A specifically modified fourway crossover design allowed evaluation of intrasubject variability of digoxin bioavailability for each dosage form.

\section{Methods}

Twelve healthy, nonobese male subjects 22 to 29 years old and weighing 63.1 to 88.9 
$\mathrm{kg}$ (mean $74.2 \mathrm{~kg}$ ) were entered in this study and randomly assigned a number (1 through 12). All subjects signed written, informed consent forms. They were instructed not to take any drugs including enzyme-inducing agents and radiodiagnostic agents for a period of $\mathbf{3 0}$ days before the start of the study or alcoholic beverages for a period of seven days preceding the initiation of or during the entire study. The timing and nature of the diet were carefully controlled.

Two 0.25-mg standard reference tablets (Lanoxin, a standard lot provided by the Biopharmaceutical Department of the FDA, Burroughs Wellcome, Lot No. 022-1) or two 0.2-mg digoxin SEG capsules (Soloxin, American Critical Care, Research Lot No. 762P) were given on two separate occasions according to Table $I$, where treatment phases $A_{1}$ and $A_{2}$ represent the tablets, and treatment phases $B_{1}$ and $B_{2}$ represent the capsules. In each case, the drug was administered together with 240 $\mathrm{ml}$ water in the morning after the overnight fast (about 10 hours). Food was allowed 4 hours after administration of the drug. Serial blood samples were collected in Vacutainers (containing $3.8 \%$ sodium citrate in aqueous solution) for a period of 48 hours following administration of the drug. After centrifugation of the sample, plasma was collected and immediately frozen until assay. A washout period of two weeks was allowed between consecutive treatment phases.

TABLE I

Study Design

\begin{tabular}{clllll}
\hline \multirow{2}{*}{$\begin{array}{c}\text { Group } \\
\text { No. }\end{array}$} & $\begin{array}{c}\text { Subjects } \\
\text { Group }\end{array}$ & \multicolumn{4}{c}{ Treatment order(phase no.) } \\
\cline { 5 - 7 } & I & II & III & IV \\
\hline 1 & $1,2,3$ & $A_{1}$ & $B_{1}$ & $A_{2}$ & $B_{2}$ \\
2 & $4,5,6$ & $A_{1}$ & $A_{2}$ & $B_{1}$ & $B_{2}$ \\
3 & $7,8,9$ & $B_{1}$ & $A_{1}$ & $B_{2}$ & $A_{2}$ \\
4 & $10,11,12$ & $B_{1}$ & $B_{2}$ & $A_{1}$ & $A_{2}$ \\
\hline
\end{tabular}

- $A_{1}$ and $A_{2}-0.5-\mathrm{mg}$ tablets; $B_{1}$ and $B_{2}-0.4-\mathrm{mg}$ capsules.

302
Digoxin concentrations in plasma and urine were determined using a radioimmunoassay procedure. ${ }^{8-10}$ Each plasma concentration was corrected for the volume of sodium citrate solution. The sensitivity of this method is $0.05 \mathrm{ng} / \mathrm{ml}$ digoxin in plasma and $2.5 \mathrm{ng} / \mathrm{ml}$ in urine. Results obtained in assaying control samples, each day that "unknowns" were run, showed excellent reproducibility. The coefficients of variation for intraday and interday variations were 6 and 8 per cent, respectively.

The experiment was carried out according to a modified four-way crossover study design to compare two formulations, each one given on two different occasions (Table I). The bioequivalence was tested by analysis of variance. The reproducibility of absorption of each digoxin formulation in each subject was determined by two different methods:

Method I. Paired observations from repeated administration of the same formulation to the same subject were plotted and the correlation was determined. While the graph provides a vivid picture of the degree of reproducibility of the absorption of digoxin, the correlation coefficient measures only the interdependence of the paired observation.

Method II. A good reproducibility requires a high degree of positive interdependence as well as large absolute agreement of the data. The intrasubject variation for each formulation was estimated from the data which were obtained for each dosage form. The standard deviations of the coefficient of variation were calculated from the differences of paired observations without correction for the mean of differences.

\section{Results}

Figures 1 and 2 depict the plasma concentration-versus-time profiles for the tablet and capsule, respectively. The data show that (a) the initial plasma digoxin concentrations for the capsule (0.4-mg dose)

The Journal of Clinical Pharmacology 


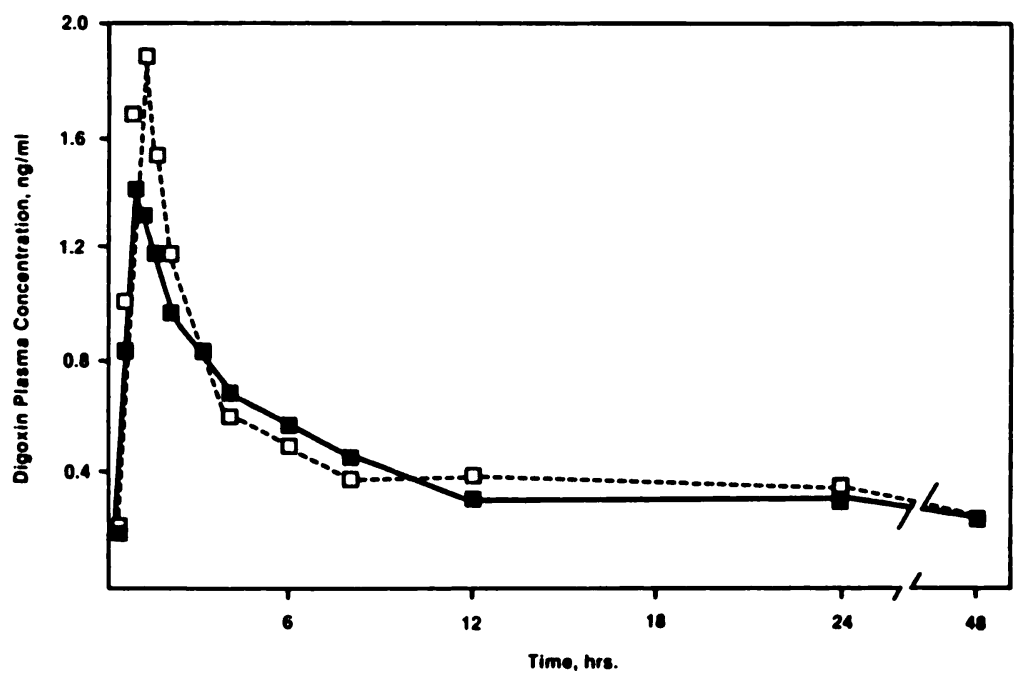

Fig. 1. Average digoxin plasma concentrations in 12 volunteers after a single oral dose: 0.5 -mg tablet in treatments $A_{1}(\square)$ and $A_{2}(\square)$.

are higher than for the tablet (0.5-mg dose); (b) the absorption profiles of individual subjects (not included) show that during the first 4 hours after drug administration.

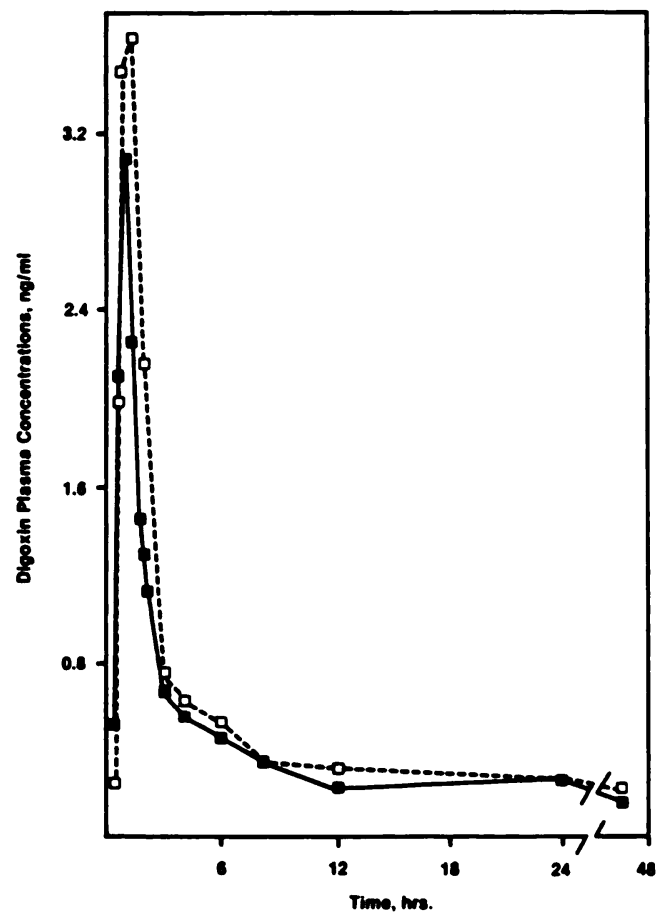

Fig. 2. Average digoxin plasma concentrations in 12 volunteers after a single oral dose: $0.4-\mathrm{mg}_{\mathrm{g}}$ digoxin SEG capsules in treatments $B_{1}(\square)$ and $B_{2}$ (ㅁ).

July 1981 absorption of digoxin from the tablet was more irregular than from the capsule; (c) the coefficients of variation $(C V)$ of observed plasma concentrations of digoxin after the capsule were smaller, in 10 out of 13 samples (between 0.75 and 24 hours), than that after the tablet (for the same 10 samples the ratio of the $C V s$, capsule/tablet, was 0.743); and (d) the plasma concentrations of digoxin during the second treatment phase in each subject were always higher than during the first treatment phase for both dosage forms, which is consistent with the observed statistically significant period effect. However, the higher concentrations of digoxin in plasma were not associated with any adverse reactions.

The peak plasma digoxin concentration for the capsule, $3.93 \mathrm{ng} / \mathrm{ml}$, was more than twice as high as that for the tablet, 1.88 $\mathrm{ng} / \mathrm{ml}$. The time to peak plasma concentration was significantly shorter for the capsule, 0.82 hour, than for the tablet, 1.24 hour. The $A U C 8$ during the 0-24- and 0-48hour intervals were 11.7 and $16.6 \mathrm{ng} / \mathrm{ml} \cdot \mathrm{hr}$, respectively, for the capsule and 11.1 and $16.7 \mathrm{ng} / \mathrm{ml} \cdot \mathrm{hr}$, respectively, for the tablet. The amounts excreted in the urine during the 0-24- and 0-48-hour intervals were 98 

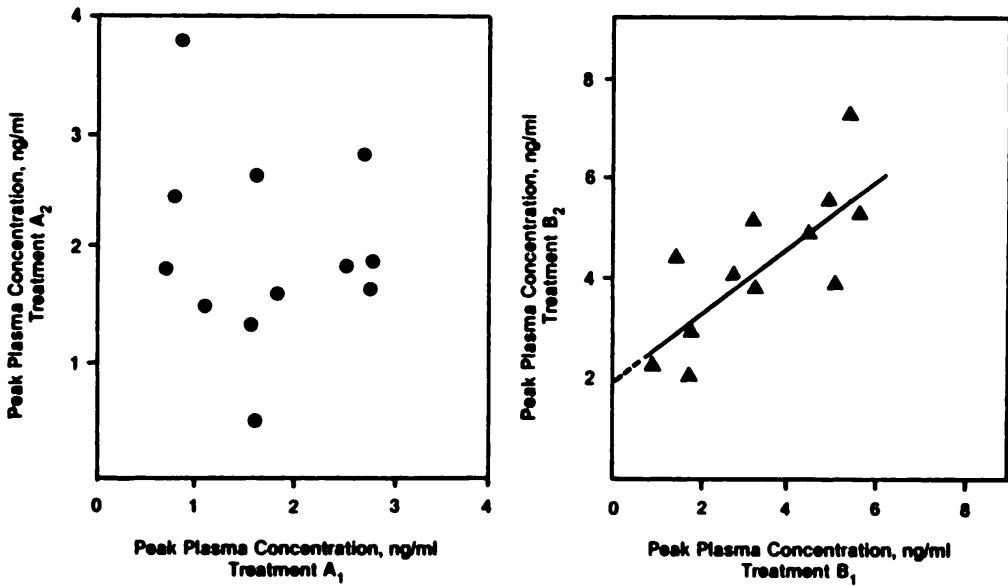

Fig. 3. Correlation of peak plasma concentrations for digoxin tablet $(\bullet)$ and soft elastic gelatin capsule ( $\Delta$ ) formulations in 12 volunteers. For this as well as for Figs. 4-6, see Table IV for correlation coefficient values.

and $142 \mu \mathrm{g}$, respectively, for the capsule and 100 and $146 \mu \mathrm{g}$, respectively, for the tablet. These values were essentially identical for both dosage forms, with an average ratio of 1.0 , indicating that the $0.5-\mathrm{mg}$ tablet dose and 0.4-mg capsule dose are bioequivalent.

Figures 3 and 4 depict the peak plasma concentrations and $A U C$ in which data from one treatment $\left(A_{1}\right.$ and $\left.B_{1}\right)$ are plotted against data from the other treatment $\left(A_{2}\right.$ and $B_{2}$ ). The renal digoxin clearance was similar after both dosage forms, but there was a significant period effect for the 0-48hour value. Following treatment phases $A_{1}$ and $A_{2}$, the average values of renal digoxin clearance were 147 and $149 \mathrm{ml} / \mathrm{min}$, respectively. These values are consistent with previously reported data., ${ }^{8,11,12}$ Following treatments $B_{1}$ and $B_{2}$, the average values of renal digoxin clearance were 154 and 137 $\mathrm{ml} / \mathrm{min}$, a difference of 12 per cent. Because of these variations, the $A U C$ and amount digoxin excreted in urine were corrected for renal clearance. Figure 5 shows the same data as in Fig. 4 after correction of $A U C$ for
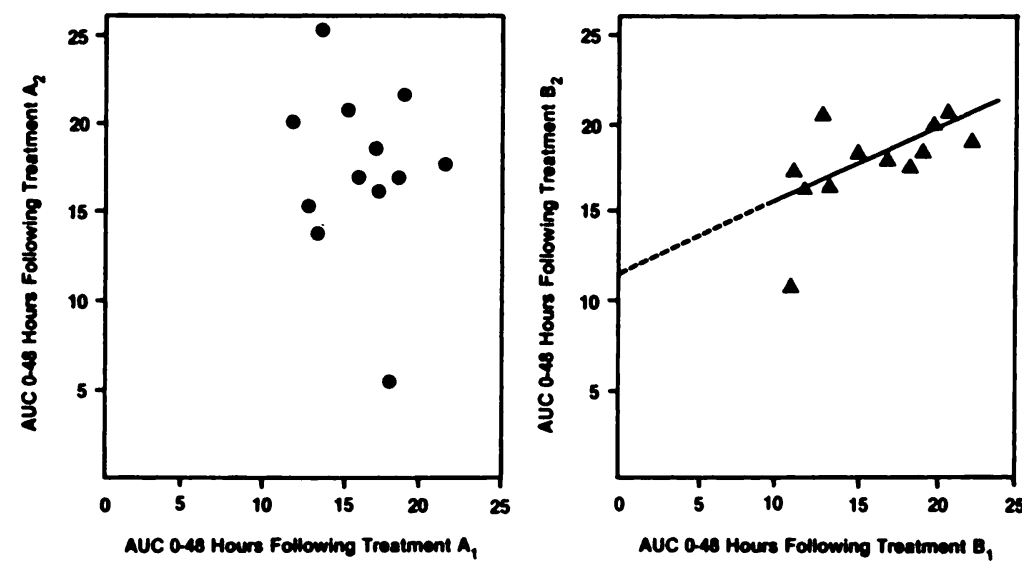

Fig. 4. Correlation of 0-48-hour AUC (ng/ml.hr) for digoxin tablet ( $(\bullet)$ and soft elastic gelatin capsule ( $\Delta$ ) formulations in 12 volunteers. 


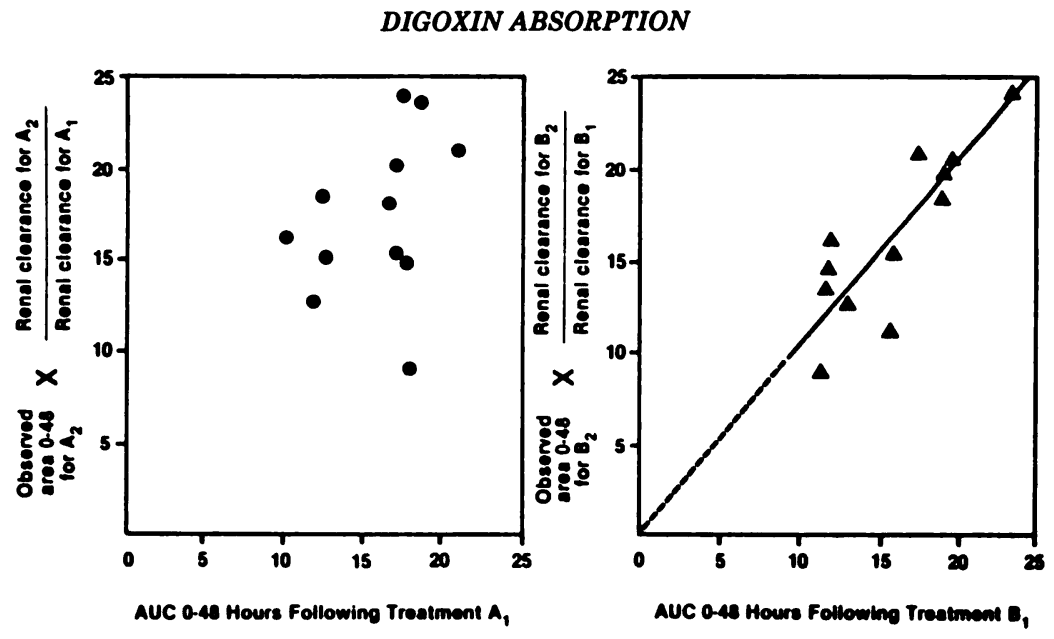

Fig. 5. Correlation of 0-48-hour AUC (ng/ml.hr) corrected for individual renal clearance for digoxin tablet $(\bullet)$ and soft elastic gelatin capsule $(\Delta)$ formulations in 12 subjects. The intercept of the soft elastic gelatin capsule relationship was not significantly different from zero. ${ }^{13}$

renal clearance. Figure 6 depicts a similar plot of amount digoxin excreted in urine.

Table II lists the correlation coefficients between values obtained in the two treatments with respect to peak time, peak plasma concentrations, $A U C$, and amount of digoxin excreted in the urine. Except for the peak time, the correlations between the pharmacokinetic parameters after the two capsule treatments were consistently high and statistically significant. There were no such correlations with respect to the tablet treatments. In one subject (no. 9), the $A U C$ and amount digoxin excreted in urine after treatment $A_{2}$ (tablet) were very low and almost one half the average values of other subjects. In order to lessen the possibility of a bias in the interpretation of the results

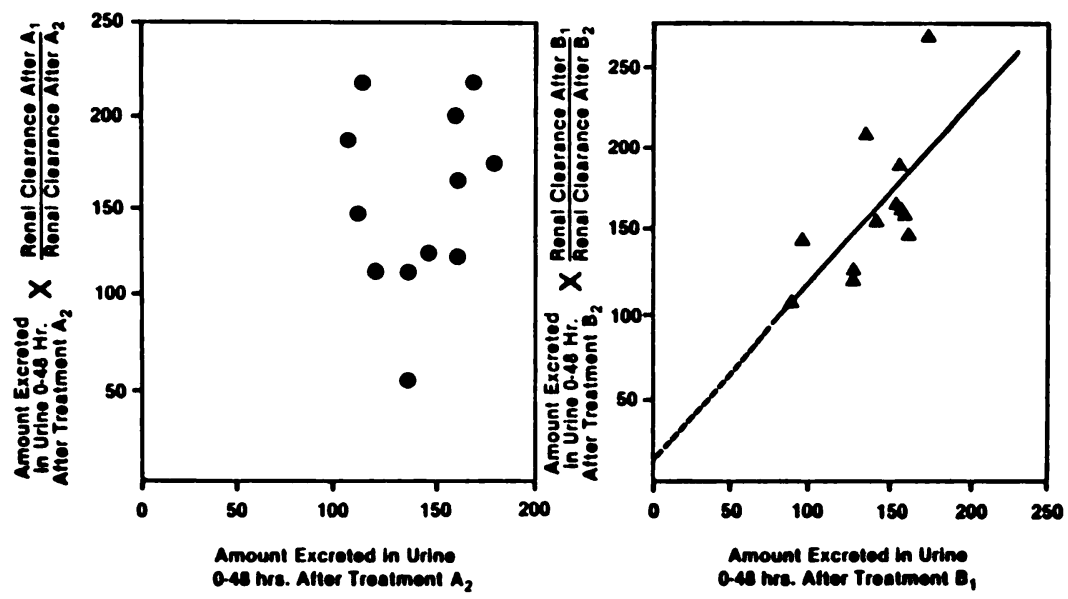

Fig. 6. Correlation of amounts of digoxin $(\mu \mathrm{g})$ excreted in the urine, 0-48 hours, corrected for renal clearance for digoxin tablet ( $\bullet)$ and soft elastic gelatin capsule ( $\Delta$ ) formulations in 12 subjects. The intercept $(18.5 \mu \mathrm{g})$ of the soft elastic gelatin capsule relationship was not significantly different from zero. $^{13}$ 
TABLE II

Correlation Coefficients Between Two Treatments With Tablets ( $A_{1}$ Versus $A_{2}$ ) or Capsules ( $B_{1}$ Versus $B_{2}$ )

\begin{tabular}{|c|c|c|c|c|}
\hline \multirow{2}{*}{$\begin{array}{l}\text { Pharmacokinetic } \\
\text { parameters* }\end{array}$} & \multicolumn{2}{|c|}{$\begin{array}{c}\text { All subjects, } \\
\quad N=12 \\
\end{array}$} & \multicolumn{2}{|c|}{$\begin{array}{c}\text { Without subject 9, } \\
\qquad N=11\end{array}$} \\
\hline & Tablets & Capsules & Tablets & Capsules \\
\hline Peak time & 0.08 & 0.18 & 0.03 & 0.16 \\
\hline Peak level & -0.14 & 0.69 & -0.19 & 0.68 \\
\hline$A U C_{0-2 \mathrm{hr}}(\mathrm{mg} / \mathrm{ml} \cdot \mathrm{hr})$ & -0.07 & 0.70 & 0.01 & 0.72 \\
\hline$A U C_{0-18 \mathrm{hr}}(\mathrm{mg} / \mathrm{ml} \cdot \mathrm{hr})$ & -0.18 & 0.62 & -0.05 & 0.64 \\
\hline$A_{0,0-24 ~ h r}$ & -0.15 & 0.59 & -0.18 & 0.67 \\
\hline$A_{0,0-10 \mathrm{hr}}$ & 0.15 & 0.72 & 0.37 & 0.77 \\
\hline
\end{tabular}

* The values were not corrected for renal clearance values.

because of data of subject 9 , statistical analysis was done with and without this subject.

Tables III and IV summarize the interand intrasubject variations, respectively, in the pharmacokinetic parameters of digoxin absorption after administration of the tablets and the capsules. On the average, the intersubject variation was slightly smaller for the capsule; the ratio of $C V$ of capsule/tablet was 0.92 . However, when data from 11 subjects were considered, there was no evidence of such a trend. The ratios of intrasubject variations of cap- sule/tablet were approximately 0.6 with or without subject 9.

\section{Discussion}

A limitation of most commonly utilized bioavailability study designs is that they allow only for assessment of intersubject variability as well as the common treatment period and group effects. A significant portion of the variability found, in therapeutic cases, may in fact be related to intrasubject variations in drug absorption. The absorption from digoxin oral dosage

\section{TABLE III}

Intersubject Variations in Pharmacokinetic Parameters of Digoxin Absorption After Administration of Tablet (A) and Soft Elastic Gelatin Capsule (B) Dosage Forms in 12 Normal Subjects

\begin{tabular}{|c|c|c|c|c|c|}
\hline \multirow{2}{*}{$\begin{array}{c}\text { Pharmacokinetic } \\
\text { parameters }\end{array}$} & \multicolumn{4}{|c|}{ Coefficient of variations (per cent) } & \multirow{2}{*}{$\left.\begin{array}{c}\text { Ratio } \\
\left(\frac{B_{1}+B_{2}}{A_{1}+A_{2}}\right.\end{array}\right)$} \\
\hline & $\overline{\mathbf{A}_{1}}$ & $\overline{A_{2}}$ & $\mathbf{B}_{1}$ & $\overline{\mathbf{B}_{2}}$ & \\
\hline Peak time & 68.9 & 20.2 & 51.7 & 26.6 & 0.88 \\
\hline Peak level & 44.2 & 42.3 & 48.8 & 34.4 & 0.96 \\
\hline$A U C_{0-24 \mathrm{hr}}$ & 22.2 & 29.2 & 25.6 & 15.7 & 0.80 \\
\hline$A U C_{0-18 \mathrm{hr}}$ & 20.3 & 27.9 & 26.2 & 16.0 & 0.86 \\
\hline$A_{0,0} 0-24 \mathrm{hr}$ & 19.4 & 27.0 & 18.5 & 28.9 & 1.02 \\
\hline$A_{\mathbf{6}, 0-68 \mathrm{hr}}$ & 18.0 & 26.5 & 19.8 & 23.4 & 0.97 \\
\hline
\end{tabular}

- In this table, as well as in Table $\mathrm{V}$, the coefficient of variations describing the intersubject variation for each treatment are equal to (standard deviation/mean) $X$ 100. $A_{1}$ and $A_{2}$ represent the two treatments, and $B_{1}$ and $B_{2}$ represent the two capsule treatments.

** Without the data from subject 9, this ratio averaged to 1.04 (range 0.93-1.20). 


\section{DIGOXIN ABSORPTION}

TABLE IV

Intrasubject Variations in Pharmacokinetic Parameters of Digoxin Absorption After Admission of a Tablet and a Soft Elastic Gelatin Capsule Dosage Form in 12 Normal Subjects

\begin{tabular}{|c|c|c|c|c|c|c|}
\hline \multirow[b]{2}{*}{$\begin{array}{l}\text { Pharmacokinetic } \\
\text { parameters }\end{array}$} & \multicolumn{3}{|c|}{ CV (per cent) all subjects, $(N=12)^{*}$} & \multicolumn{3}{|c|}{ CV (per cent), without subject 9} \\
\hline & Tablet & Capsule & $\begin{array}{c}\text { Ratio } \\
\text { capoule/ } \\
\text { tablet }\end{array}$ & Tablet & Capsule & $\begin{array}{c}\text { Ratio } \\
\text { capsule/ } \\
\text { tablet }\end{array}$ \\
\hline Peak time & 63.9 & 38.3 & 0.60 & 91.4 & 56.8 & 0.62 \\
\hline Peak level & 44.7 & 28.3 & 0.63 & 73.2 & 33.3 & 0.45 \\
\hline$A U C_{0-21 \mathrm{hr}}$ & 26.6 & 15.5 & 0.58 & 32.3 & 20.8 & 0.64 \\
\hline$A U C_{0-18} \mathrm{hr}$ & 26.0 & 15.8 & 0.61 & 30.3 & 21.5 & 0.71 \\
\hline$A_{0,0-24 \mathrm{hr}}$ & 26.4 & 17.0 & 0.65 & 37.4 & 16.9 & 0.45 \\
\hline$A_{0,0-0,8 \mathrm{hr}}$ & 21.1 & 12.0 & 0.57 & 23.0 & 15.7 & 0.68 \\
\hline
\end{tabular}

* Per cent coefficient of variation calculated as described by method II.

forms in particular has been erratic and has been a major concern in therapy. In this study, as a part of a new oral dosage form development, an attempt was made to account for both inter-and intrasubject variations in absorption of digoxin from a digoxin SEG capsule and a standard reference tablet. The modified four-way cross- over study used in this study allowed the simultaneous evaluation of both the reproducibility of absorption in the same subject as well as the assessment of the bioavailability of the two digoxin dosage forms.

The absorption of the 0.4-mg capsule was found to be much faster, producing peaks twice as high as that of the $0.5-\mathrm{mg}$ tablet. In

\section{TABLE V}

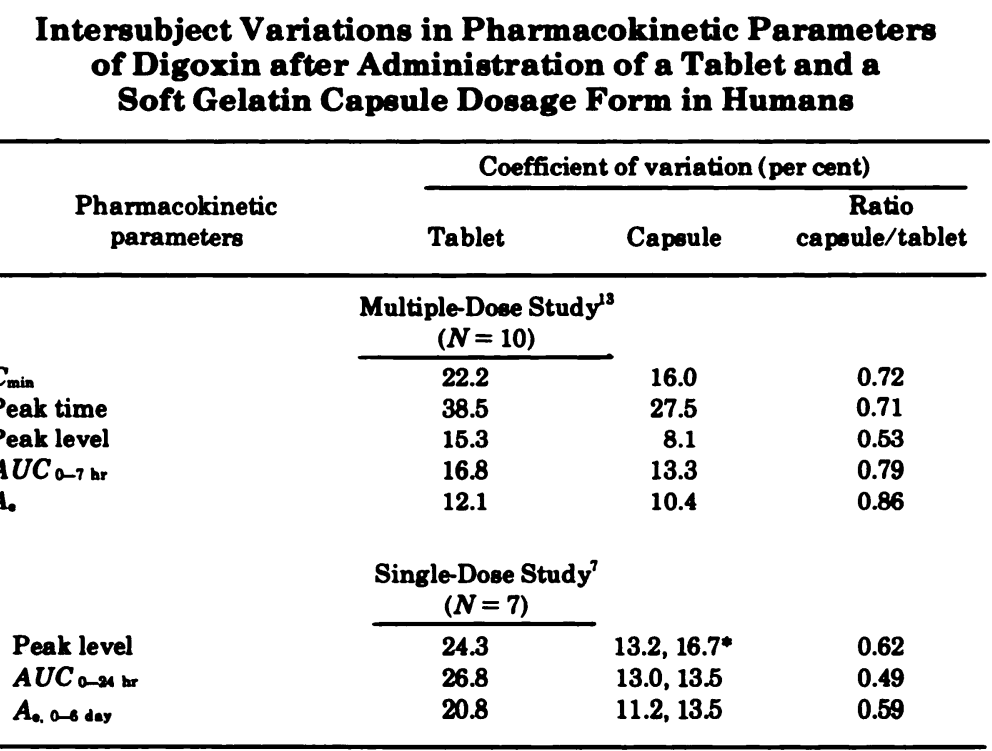

* Two sets of data representing two capsules differing in size. 
the case of both dosage forms, higher plasma concentrations were observed during the second treatment. This could be due to variations in absorption within the same subject and/or possible changes in physiologic factors influencing the renal excretion of digoxin. Interestingly, a 12 per cent variation in renal clearance was found for the capsule and not for the tablet. This indicates that for the tablet the variations in the pharmacokinetic parameters are almost entirely related to variations in absorption.

In general, considering the data from all subjects, the intersubject variability was smaller for the capsule. Excluding the data from one subject, this variability was no longer apparent. In this study, there was a significant period effect which may have obscured the existence of any intersubject variability. Table $\mathrm{V}$ summarizes the intersubject variations in pharmacokinetic parameters from two studies ${ }^{3,4}$ which tested digoxin SEG capsules and tablets. The data showed significantly less variation for the capsules.

One method to assess reproducibility of digoxin absorption in the same subjectis to plot the data from one treatment with a given dosage form versus the data obtained from the second treatment with the same dosage form. In this study, such plots for both the standard reference tablet and the digoxin SEG capsule were prepared with respect to peak plasma concentration (Fig. 3), $A U C_{0-48 \mathrm{hr}}$ (Figs. 4 and 5), and amount of digoxin excreted in the urine (Fig. 6). Ideally, each relationship should yield a straight line with a slope of unity and an intercept of zero. Additionally, as noted above, the renal function may affect the observed parameters. Therefore, the parameters were also corrected for renal effect.

The relationship between values obtained in the two tablet treatments, with respect to peak plasma concentration, $A U C$, and amount of digoxin excreted in the urine, showed no significant correla- tions. Correction of the data for renal digoxin clearance did improve the correlations, but they remained statistically insignificant. These observations clearly point out the lack of reproducibility of absorption of digoxin from the tablet in the same subjects. In contrast, there was a significant positive correlation between values of peak plasma digoxin concentration, $A U C$, and amount of digoxin excreted in the urine which were obtained in the two treatments of digoxin SEG capsule $\left(B_{1}\right.$ and $B_{2}$ ) in the same subject. Consistent with the observation of possible renal effect on bioavailability, when the individual data were corrected for renal digoxin clearance the correlation did improve significantly and particularly that for the $A U C$ became greater $(r=0.850, P<0.001)$ with a slope equal to 0.971 , very close to unity. Additionally, the correlation coefficients between the ratio of peak plasma concentration and $A U C$ in treatment 1 versus the same ratio in treatment 2 of each dosage form were determined by Pearson's equation. ${ }^{14}$ These correlation coefficients were 0.589 and 0.0017 for the SEG capsule and tablet, respectively, and were essentially identical to the values obtained by the conventional method. These results emphasize the superiority of the capsule also in terms of reproducibility of absorption in the same subjects.

Another method of examination of the intrasubject variations in absorption of digoxin is to compare the coefficients of variation of different pharmacokinetic parameters, In this study, both the inter- and intrasubject variations in absorption are dependent on the dosage form. The intrasubject variations, however, do provide more definitive information, since usually all the factors except absorption are the same within the same subject. As indicated in Table IV, the intrasubject variation in the absorption of digoxin from the capsule was about 60 per cent of the variations within the tablets with respect to peak plasma digoxin concentration, time to

The Journal of Clinical Pharmacology 


\section{DIGOXIN ABSORPTION}

peak, $A U C$, and amount of digoxin excreted in the urine. These results substantiate the poor subject-to-subject variation in absorption of digoxin from the tablet when compared to the capsule.

The results of this study are consistent with those reported in the literature comparing a tablet with a different brand of digoxin SEG capsule. In one study, steadystate plasma digoxin concentration after a tablet was compared with that after a SEG capsule in 20 patients. ${ }^{13}$ There were significantly greater variations between two serum digoxin concentrations in the same subjects after the tablet (18 per cent) than after the capsule (11 per cent). In another study, variations in steady-state plasma concentrations were examined after administration of a tablet and a capsule in 10 normal subjects. ${ }^{4}$ Using three steady-state plasma digoxin concentrations in the same subject, coefficients of variation of 22 and 16 per cent were observed for the tablet and capsule, respectively.

A single- and multiple-dose study carried out by other investigators on the same brand of tablet and capsule showed essentially identical results, i.e., the bioavailability of the capsule is superior to that of the tablet. ${ }^{15}$ The data described in this study and in the literature indicate that the reference tablet which is used as a standard dosage form to test oral absorption may produce considerable variability in clinical response due to the variations in its in vivo absorption. Thus, from the clinical standpoint, the use of a dosage form that minimizes the intrapatient variations will also result in improved therapy and fewer deleterious effects.

\section{References}

1. Binnion PF. A comparison of the bioavailability of digoxin in capsule, tablet and solution taken orally with intravenous digoxin. J Clin Pharmacol. 1976; 16:461-467.

2. Ghirande P, Catenazzo G, Mantoro O, Merotti GC, Mazzo A. Bioavailability

July 1981 of digoxin in a new soluble pharmaceutical formulation in capsules. $J$ Pharm Sci. 1977; 66:267-269.

3. Johnson BF, Bye C, Jones G, Sabey GA. A completely absorbed oral preparations of digoxin. Clin Pharmacol Therap. 1976; 19:746-751.

4. Johnson BF, Smith G, French J. The comparability of dosage regimens of Lanoxin tablets and Lanoxicaps. Br J Clin Pharmacol. 1977; 4:209-211.

5. Lindenbaum J. Greater bioavailability of digoxin solution in capsules. Studies in the postprandial state. Clin Pharmacol Therap. 1977; 21:278-282.

6. Mallis GI, Schmidt DH, Lindenbaum J. Superior bioavailability of digoxin 80lution in capsule. Clin Pharmacol Therap. 1975; 18:761-768.

7. Rodgers EM, Dobbs SM, Kenyon WI, Poston JW. Evaluation of digoxin capsules in outpatients. $\mathrm{Br} \mathrm{Med} J$. 1977; 2:234-235.

8. Wagner JG, Stoll RG, Weidler DJ, Ayers JW, Hallmark MR, Sakmar E, Yacobi A. Comparison of the in-vitro and in-vivo release of digoxin from four different soft gelatin capsule formulations. J Pharmacokinet Biopharm. 1977; 7:147-158.

9. Stoll RG, Christensen MS, Sakmar E, Wagner JG. The specificity of the digoxin radioimmunoassay procedure. Res Comm Chem Pathol Pharmacol. 1972; 4:503-510.

10. Wagner JG, Hallmark MR, Sakmar E, Ayers TW. Sensitive radioimmunoassay digoxin in plasma and urine. Steroids. 1977; 29:787-807.

11. Wagner JG, Christensen M, Sakmar E, Blair D, Yates JD, Willis PW III, Sedman AJ, Stoll RG. Equivalence lack in digoxin plasma levels. JAMA 1973; 224:199-204.

12. Wagner JG. Pharmacokinetic parameters estimated from intravenous data by uniform methods and some of their uses. J Pharmacokinet Biopharm. 1977; 5:161-182. 
13. Snedecor GW, Cochran WG. Statistical Methods, 6th ed. Ames, Iowa: Iowa State University Press; 1976:419-433.

14. Pearson K. Mathematical contribution to the theory of evolution. On a form of spurious correlation which may arise when indices are used in the measurement of organs. Proc Roy Soc (London). 1897; 60:489-499.
15. Lloyd BL, Greenblatt DJ, Allen MD, Harmatz JS, Smith TW. Pharmacokinetic and bioavailability of digoxin capsules, solution and tablets after single dose and multiple doses. Am J Cardiol. 1978; 42:129-136.

Reprint requests to: Avraham Yacobi, Ph.D., Research and Development Department, American Critical Care, 1600 Waukegan Road, McGaw Park, Ill. 70085. 